
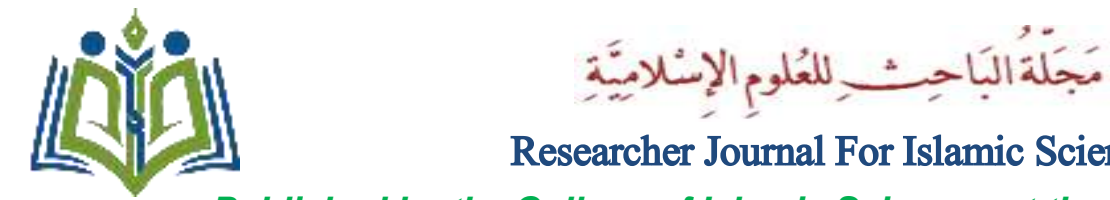

Researcher Journal For Islamic Sciences

Published by the College of Islamic Sciences at the University of Fallujah

ISSN p.p:2708-3993 / ISSN o.l: 2708-4000

Vol;2- Issue;1/ (2020-2021)

\title{
The Impact Of The Environment On The Poets Of The First Abbasid Era، (Images And Meaning)
}

\author{
Assistant teacher: Baqir jlwy alwan / University of Fallujah، College of \\ administration economics / baqir-jlwy@uofallujah.edu.iq/ 07733654299
}

Abstract: The environment has occupied a prominent position in the literary text until its subject became a key to the text and deciphering it by searching the secrets of these poetic texts and the environment at the same time. As far as my specialization as concerned my reading of poetic texts led me in the first Abbasid era to delve into the knowledge of the most important influences and components of this poetry. A careful look at these texts reveals to us a fact on which no two disagree it is the reality of the environment and its great impact on the refinement and formation of the poet's personality on the one hand, as well as casting a shadow over the poet's linguistic dictionary and the meanings، significance and expressions of poetry this fact refers to the specificity of the impact of the environment and its role in determining the characteristics of poetry and understanding its movement as pointed out by a number of critics، these and other motives focused my attention on this subject and made it a special starting point from which to research the issue of the environment، poetry and the sign between them.

Keywords: (environment، Abbasid poetry، relationship، influential aspects). 


\section{أثر البيئة في شعراء العصر العباسي الأول (صورٌ ومعالٍ)}

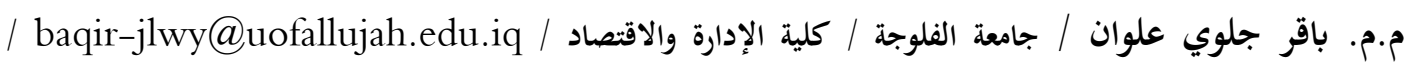

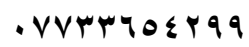
الملتخص:

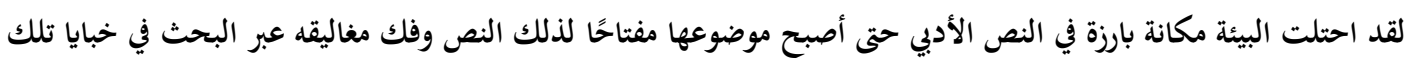

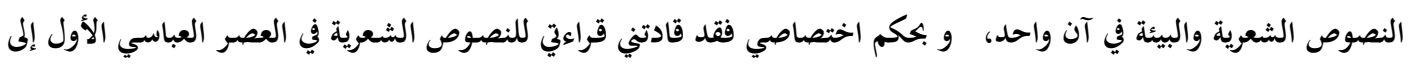

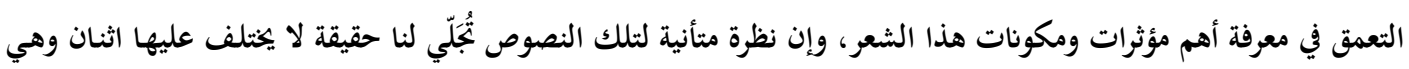

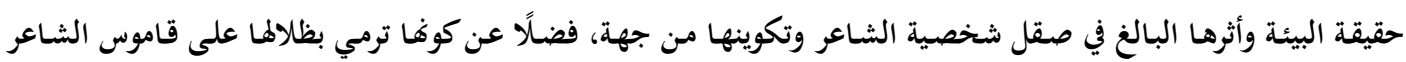

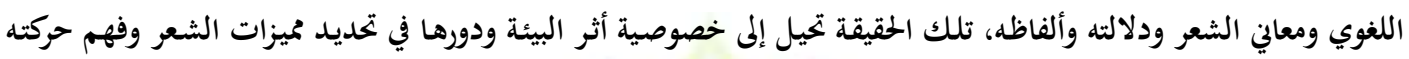

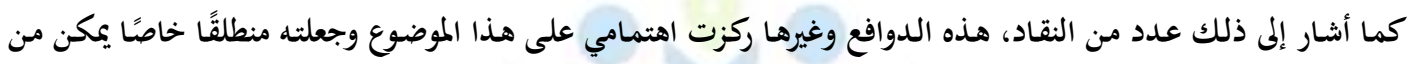
خلاله البحث في قضية البيئة والشعر والعلاقة بينهما. الكلمات المفتاحية: البيئة- الشعر العباسي- علاقة البيئة بالشعر- الجوانب المؤثرة.

$11 \leqslant$

Doi:10.37940/RJIS. 2021.2.1.4 


\section{أثر البيئة في شعراء العصر العباسي الأول (صورٌ ومعالٍ)

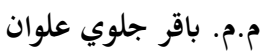

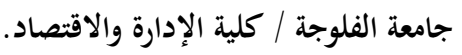

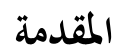

(الإنسان ابن بيئته) مقولة شائعة وصحيحة ودقيقة، وقد قادتني هذه العبارة إلى تتبع أثر البيئة في الشاعر على وجه الخها

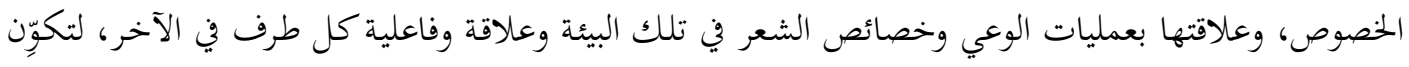

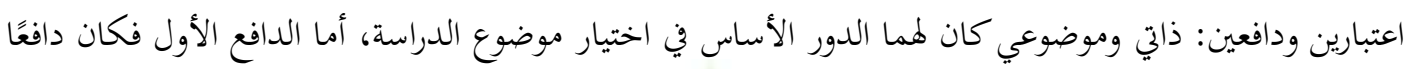

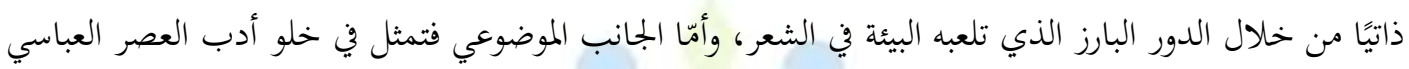

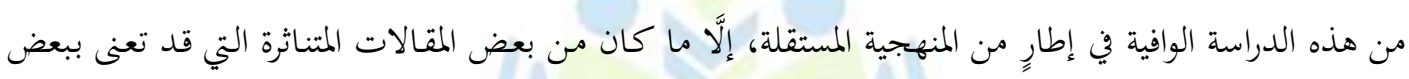

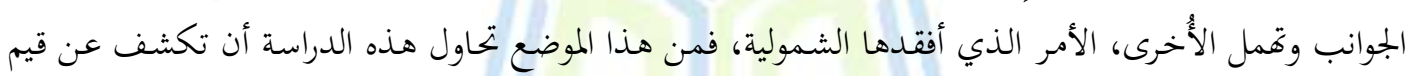

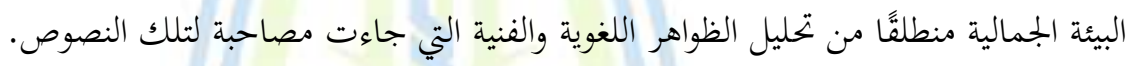

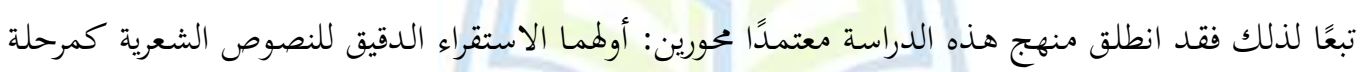

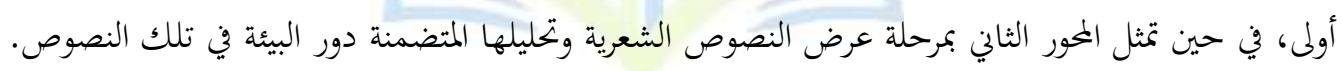

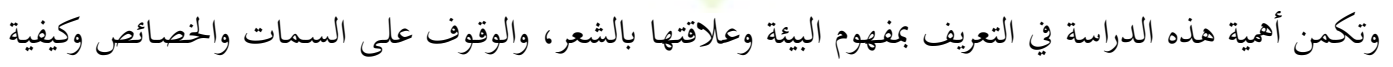

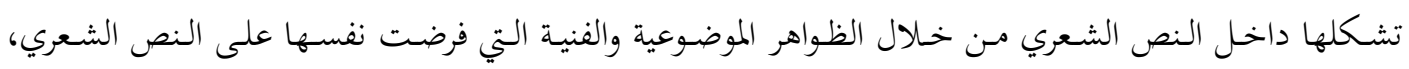

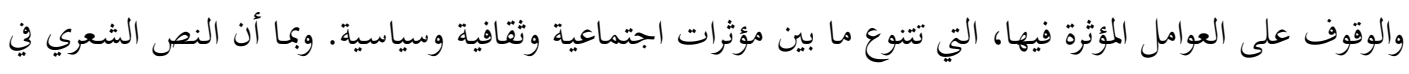

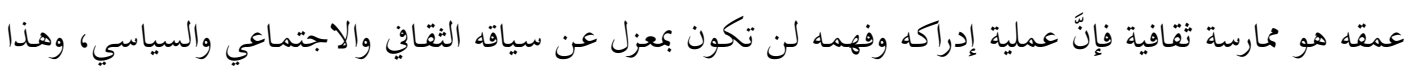

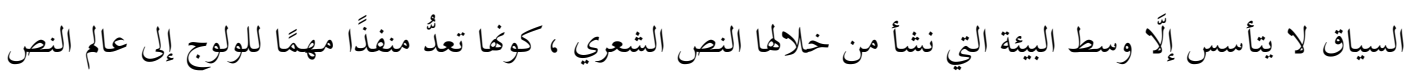

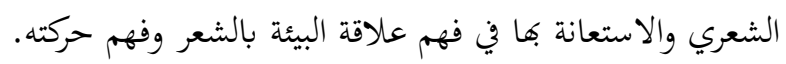

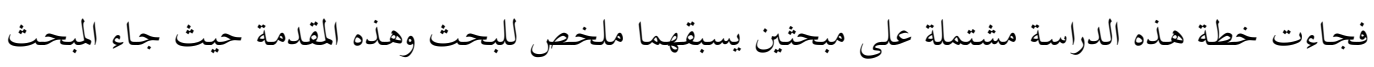

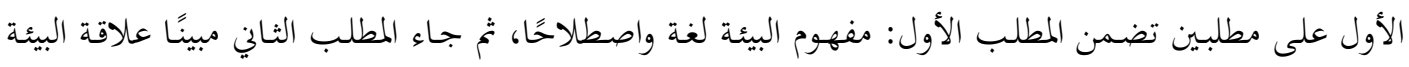

110

Doi:10.37940/RJIS. 2021.2.1.4 
بالشعر ودورها في إبداع التصوير وسعة الخيال، والذي كان أقصر من المبحث الثاني؛ لما تضمنته ضرورة البحث، ثم المباء

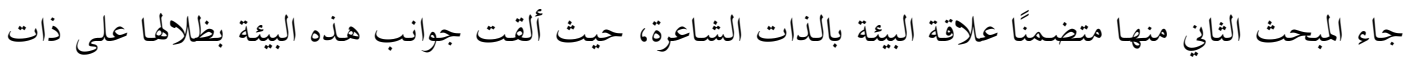

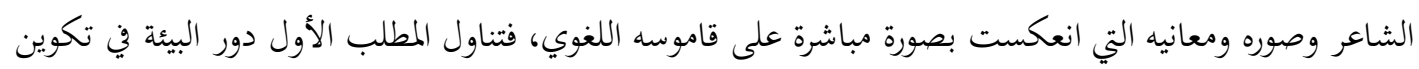

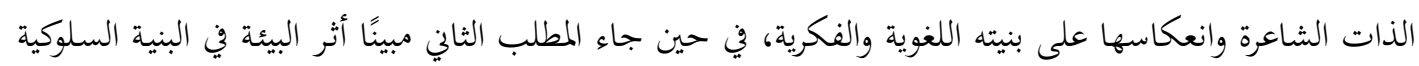

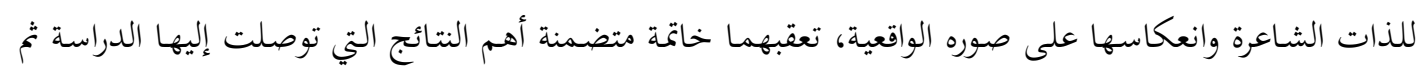
قائمة المصادر والمراجع.

\section{المبحث الأول: مفهوم البيئة وعلاقتها بالشعر.} المطلب الأول: مفهوم البيئة لغة واصطلاحًا:

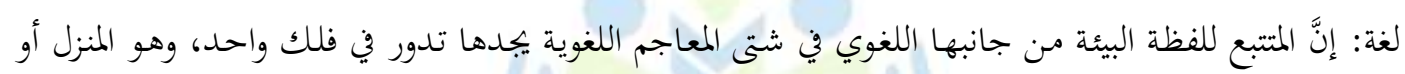

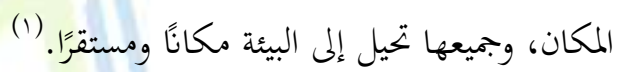

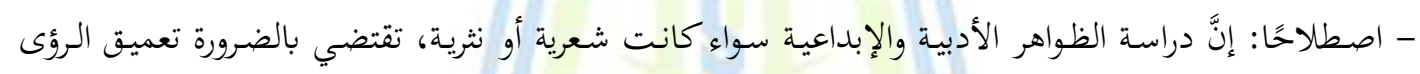

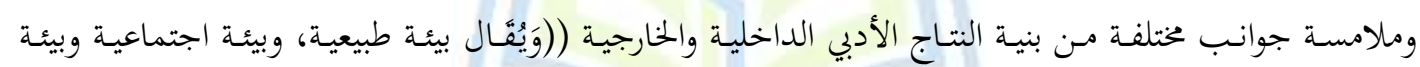

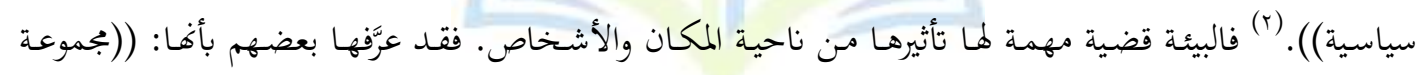

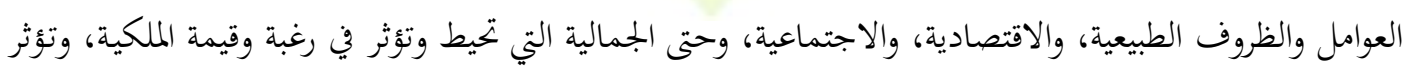

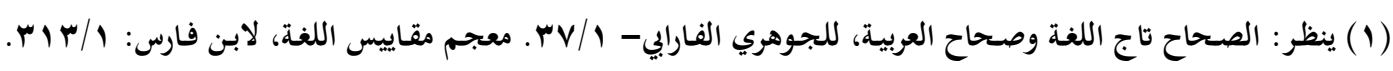

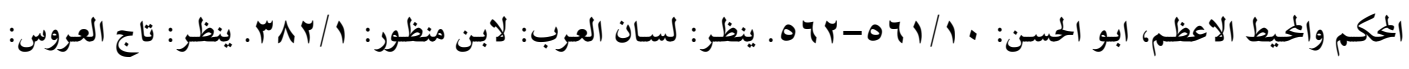

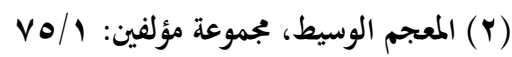

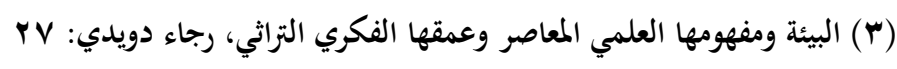

117

Doi:10.37940/RJIS. 2021.2.1.4 
في حياة الناس))."( وقد جعلنـا من هـذا التعريف منطلقًا لإرساء قواعد هـا البحث لتتبع الأثر البيئي داخل

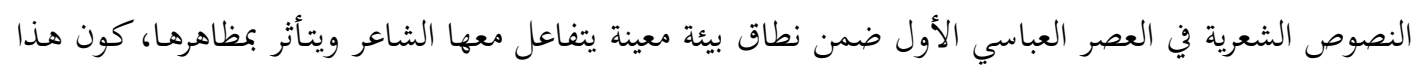

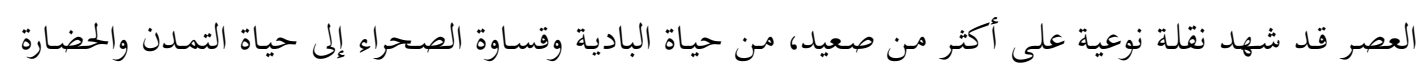
والعمران والتوجه الثقافي والمعرئ. - المطلب الثاني: العلاقة بين البيئة والشعر وأثرها في توليد المعاني وإبداع الثصوير.

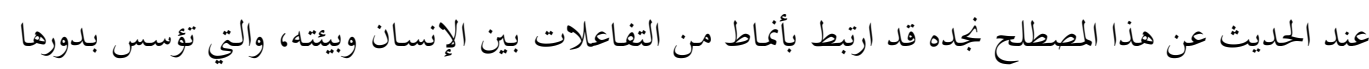

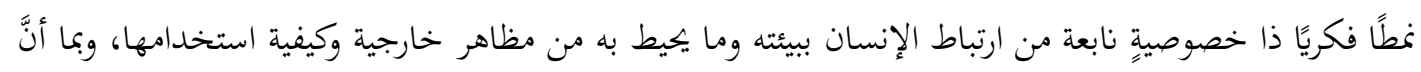

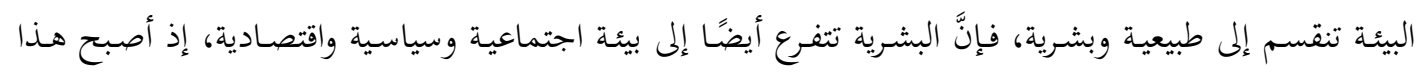

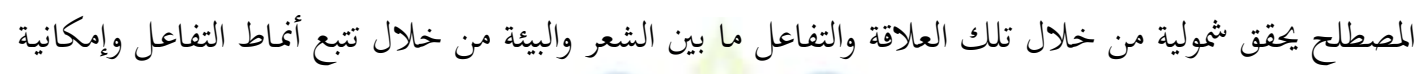

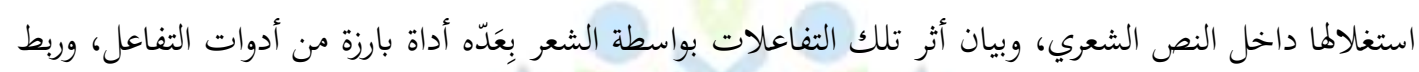
تلك العلاقة ما بين الإنسان وبيئنه.

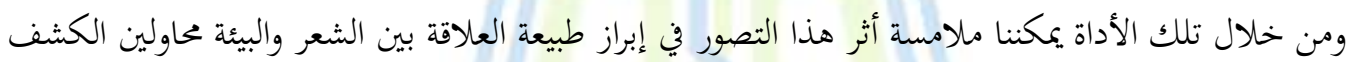

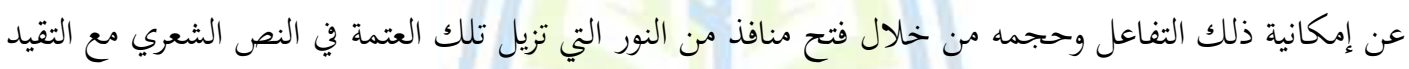

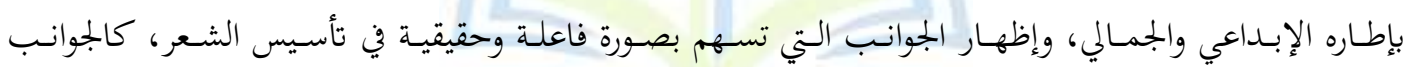

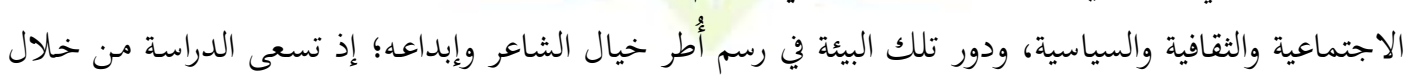

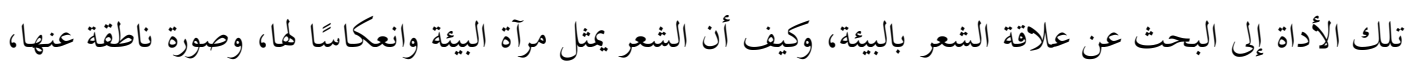

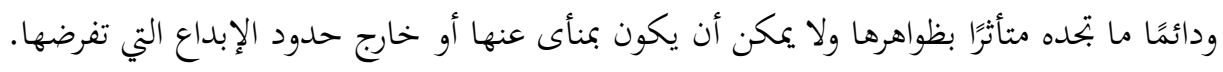

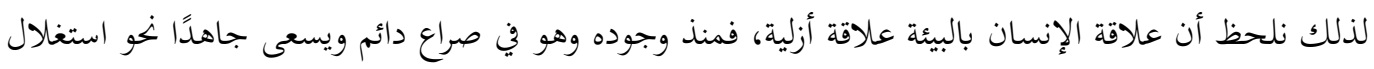

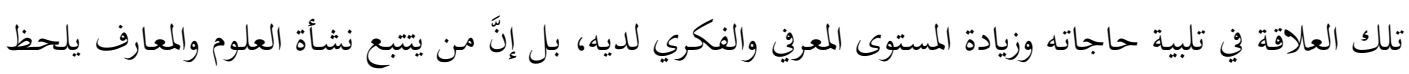

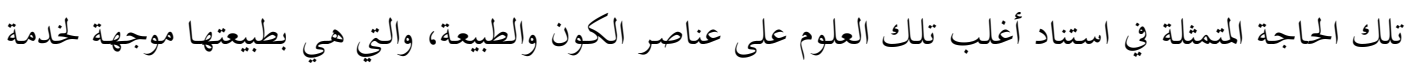

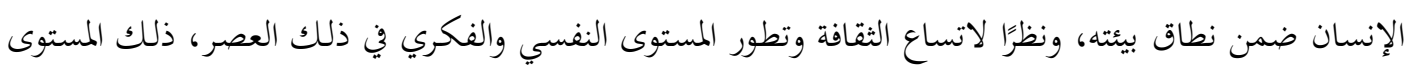


ساعد الشاعر كثيرًا على توليد المعاني ورسم الصور الفنية وتركيبها من عناصر لم تكن متداولة ومعهودة من قبل،

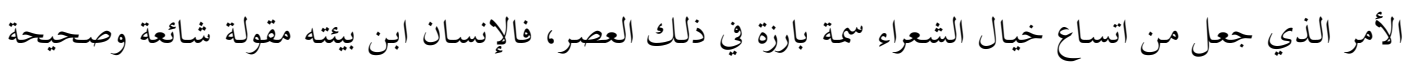

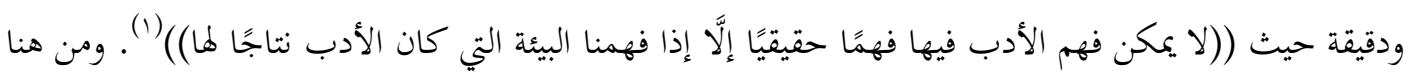

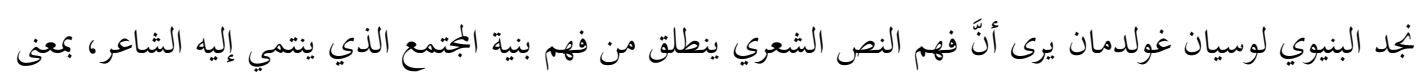

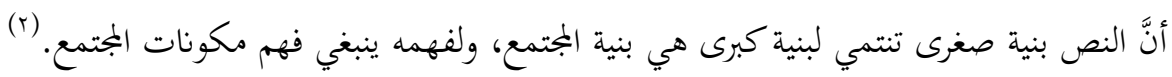

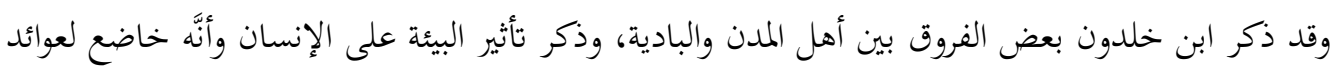

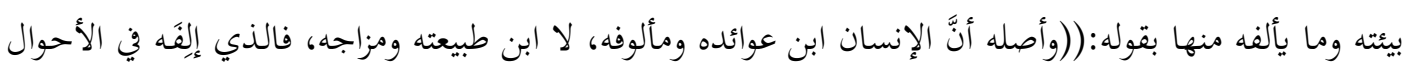

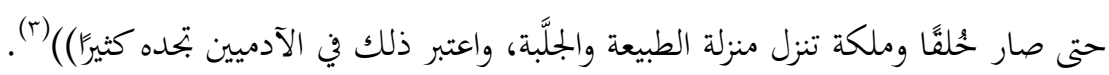

المبحث الثالي: علاقة البيئة بالذات الثاعرة وأثرها في قاموس الثاعر اللغوي وصوره الفنية: المطلب الأول: دور البيئة في البنية التكوينية للذات الثاعرة وانعكاسها على بنيته اللغوية والفكرية:

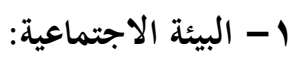

لا يخفى على أحد تلك الأهمة التي يلعبها الدور الاجتماعي في التأثير على سلوك الإنسان وألفاظه من

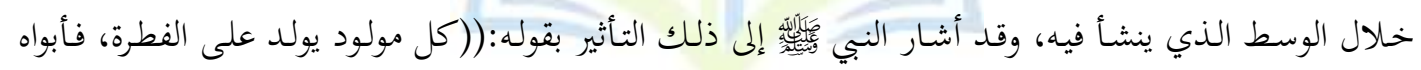

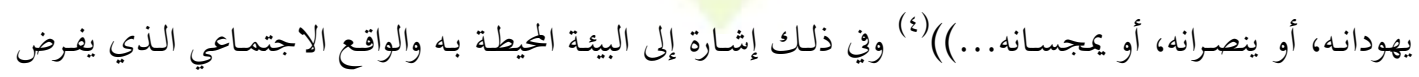

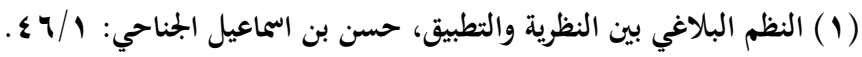

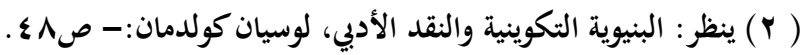

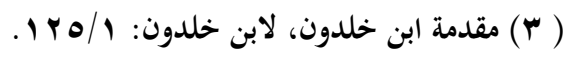

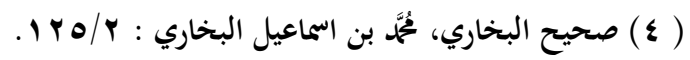

111 
ارتداداته على الشاعر بشكل خاص وعلى الإنسان بشكل عام، فالبيئة الاجتماعية واحدة من تلك الظواهر التي

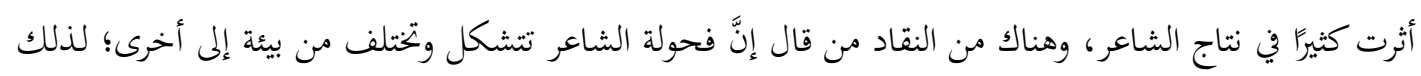

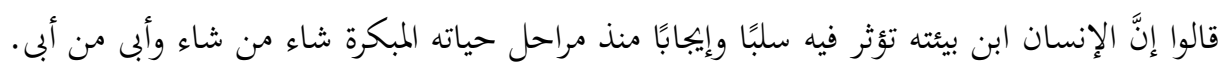

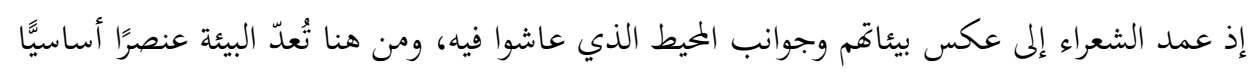

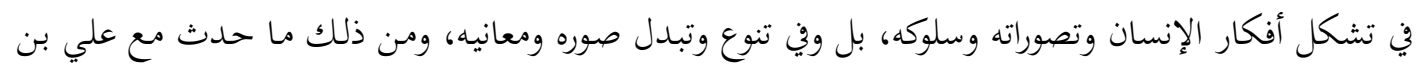

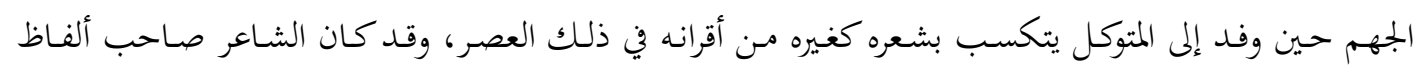

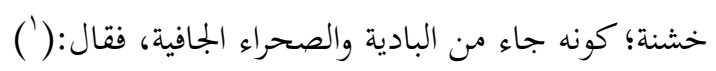

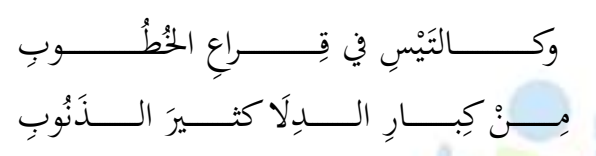

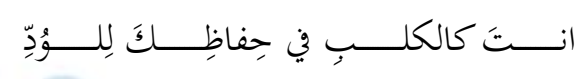

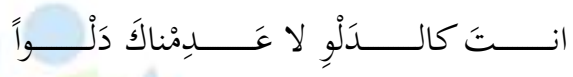
وقد أنكر حاشية الخليفة عليه ذلك المدح حين شبه الخليفة بالكلب والتَّيس، والخليفة فهم مغزى ذلك المدحح وقوته، وفطن إلى رقة مقصده، وخشونة لفظه كون الشاعر قد جاء من بيئة جافية وهي البادية، وهو ما أشار إليه اليه

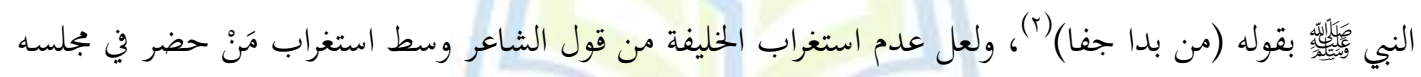

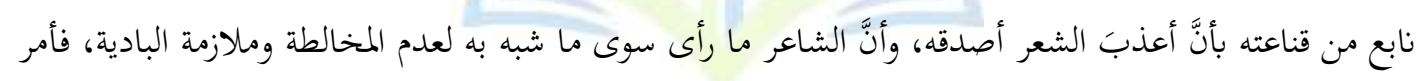

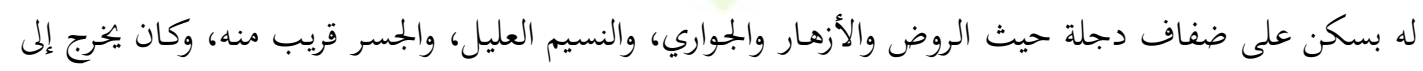

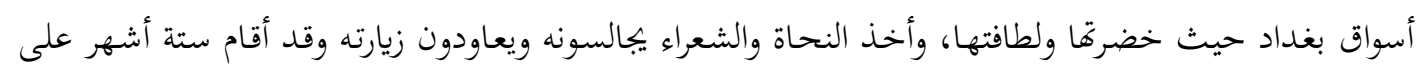


تلك الحالة. (1) فأرسل الخليفة بعد فترة في طلبه واستنشده ما كتب بعد هذه الفترة، فأنشد قصيدته التي يتغنى بما

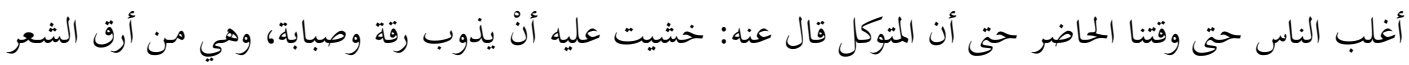
وأعذبه، فقال:( )

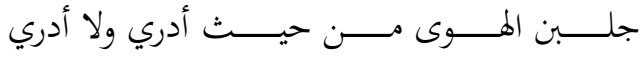

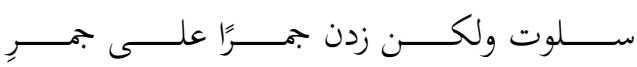

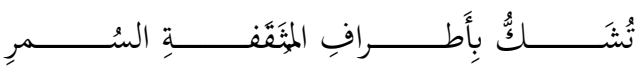

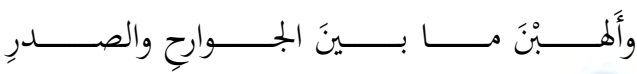

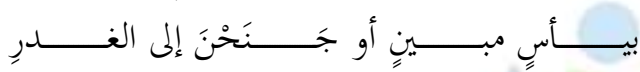

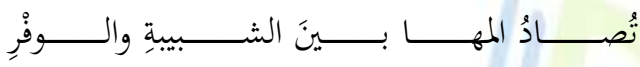

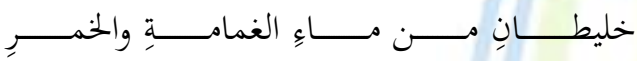

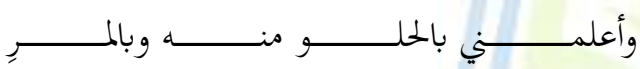

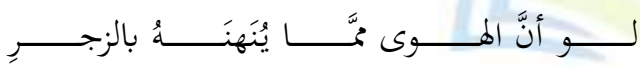

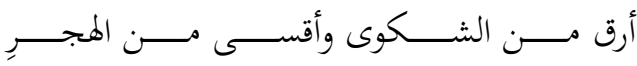

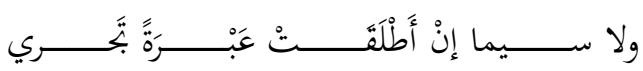

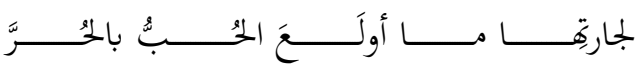

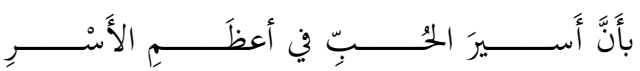

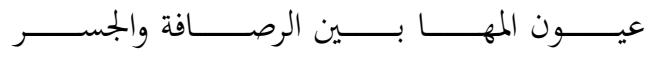

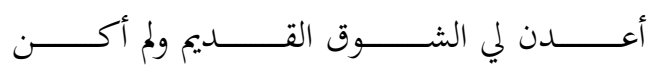

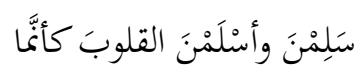

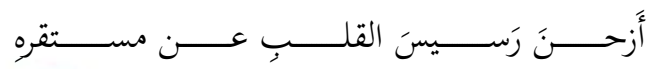

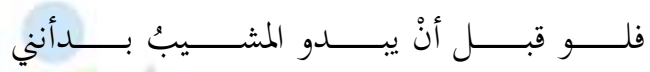

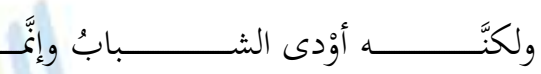

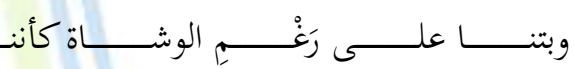

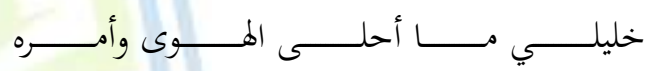

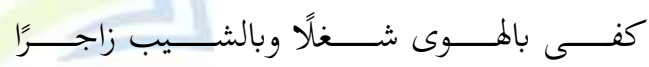

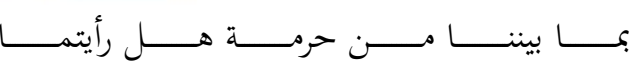

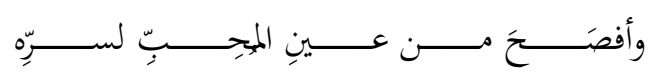

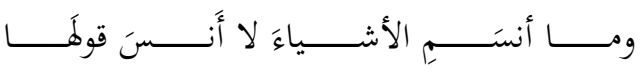

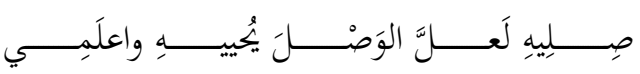

IT. 
فهذا التصوير البديع الذي أطلقه الشاعر إن دلَّ على شيء فإنما يدل على دور البيئة في بناء شخصية الشاعر

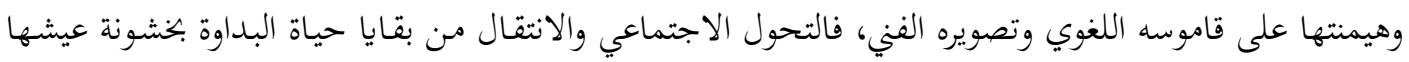

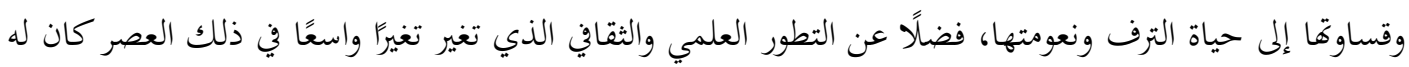

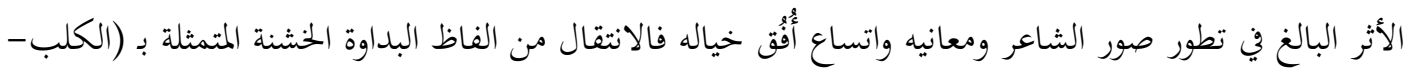

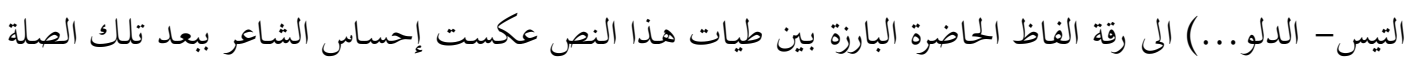

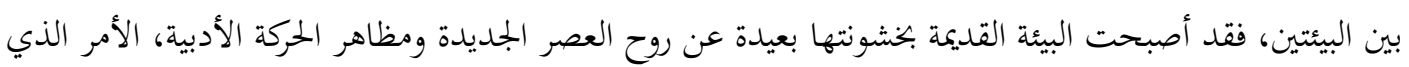

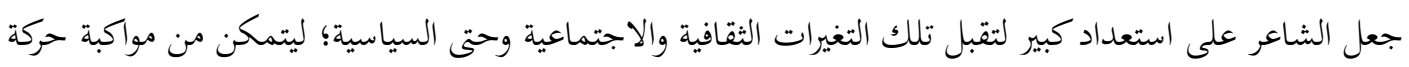

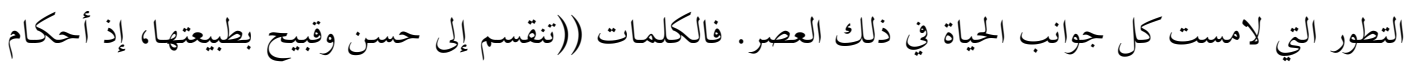

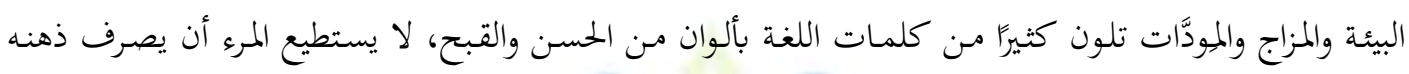

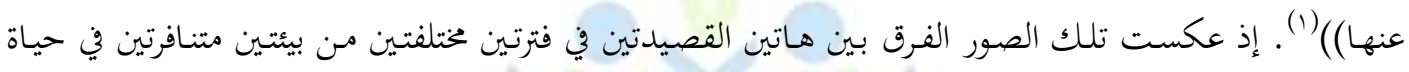
الشاعر، وكذا فقد ساهمت بدور أكبر في إبراز دور البيئة وأثرها في نتاج الشاعر وقاموس ألفاظه.

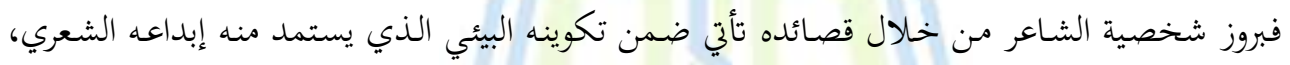

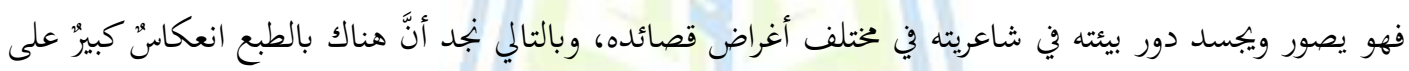

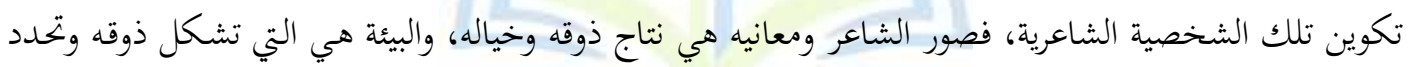

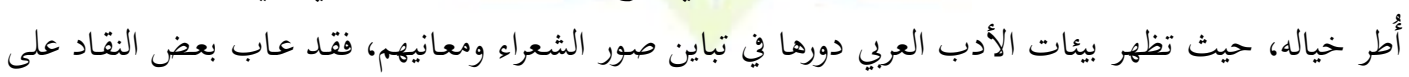
أبي تمام قوله: (r)

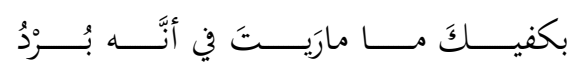

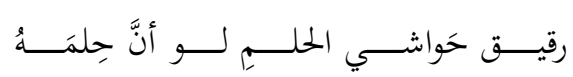

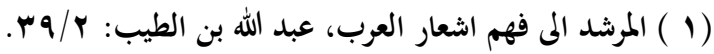

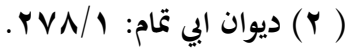

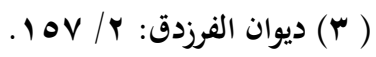

$|Y|$

Doi:10.37940/RJIS. 2021.2.1.4 
بينما كانت العرب في البادية والصحراء تتفاخر بحلمها وشدة غضبها، وتتغنى بقول الشاعر:(1)

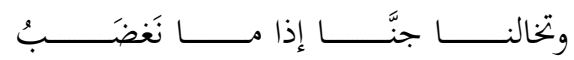

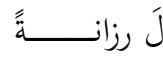

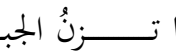
أحلامنــ

هذان الموقفان من شاعرين مختلفين يعكسان دور البيئة وضلوعها في تكوين شاعرية الشاعر ولغته الشعرية، فأبو تمام حين أطلق خطابه أطلقه من بيئة اجتماعية تعكس رقة الحياة ورهافة الحس وعذوبة اللغة في تلك المرحلة، وليس من خيمة وسط الصحراء حيث صعوبة الحياة وخشونة الألفاظ، فهذا التفاوت في رقة الألفاظ بين الشاعرين لاشكُّ أنه نابع من الفرق بين البيئة التكوينية للشاعرين (البادية - والحاضرة)، فأثر العامل البيئي في الشعر قد تنبه

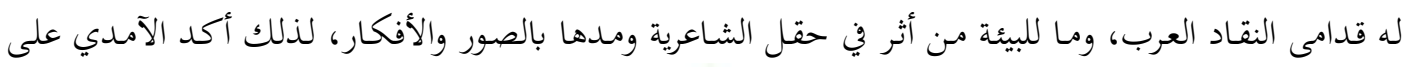

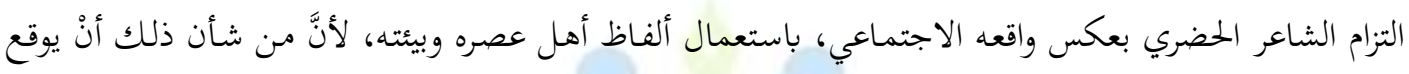
الثاعر فيما هو ليس محمودًا، وأن يتجنب في شعره الوحشي من الألفاظ ((فمن شأن الشاعر الحضري أن يأتي في شعره بالألفاظ العربية المستعملة في كلام الحاضرة، وإن اختار أن يأتي بما لا يستعمله أهل الحضر ... أنْ يجعله متفرقًا في تضاعيف ألفاظه ويضعه في مواضعه، فإن الككام أجناس، وإذا أتى منه شيء مع غير جنسه باينه ونافره وأظهر

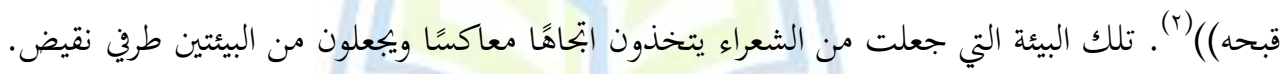

\section{r- ب البيئة العلمية والثقافية:}

تُعدّ الثقافات الجديدة التي اطَّلع عليها الشعراء في تلك المرحلة من الدوافع الأساسية التي عكستها بيئة

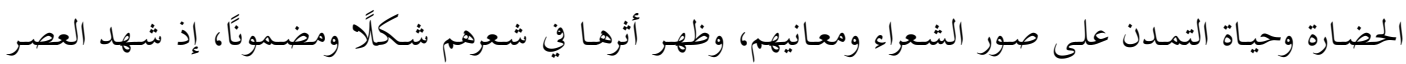

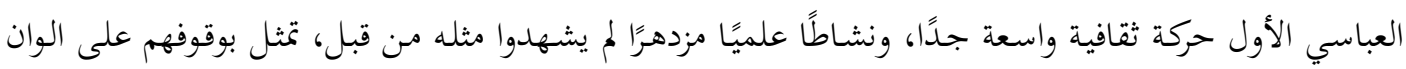
الثقافات والعلوم والمعارف، والتي دفعتهم إلى التعبير بما يتناسب وحجم ذلك الرقي الثقافي والتقدم العلمي، فبرزت سمة توليد المعاني نتيجة للتأمل العقلي والرغبة في الابتكار، تلك السمة كان لها اتصال وثيق بالعمق الثقافي وقوة الشاعر على تأمل الحياة وفهمم بحاربها، مما جعل مـن تلك البيئة معينًا خصبًا للشاعر المتمكن مـن تلقي وحيها

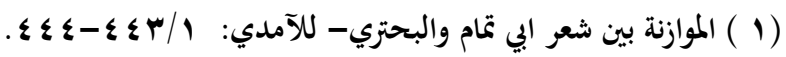
IrT 


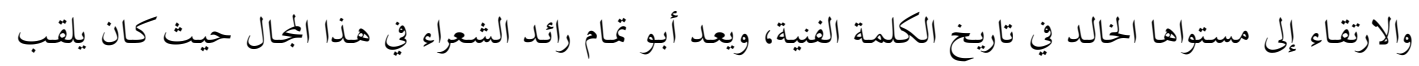

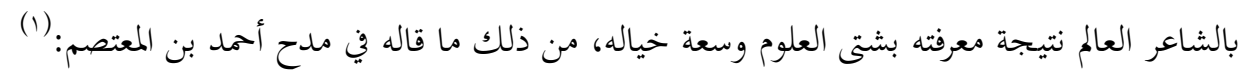

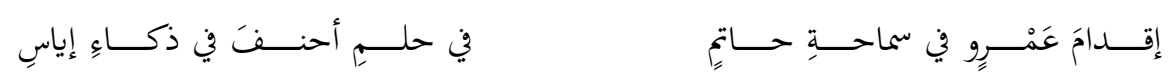

فالشاعر في هذا البيت أظهر مخزونه المعرفي والثقافي من اعلام المجتمعات التي سبقته بذكر مآثرهم بالشجاعة

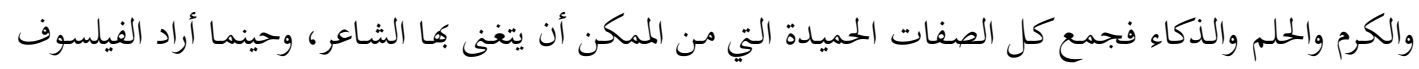

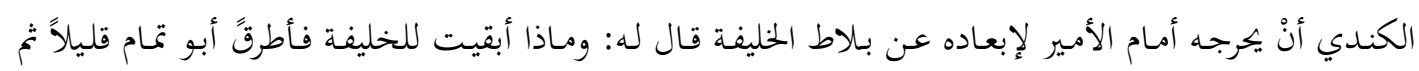

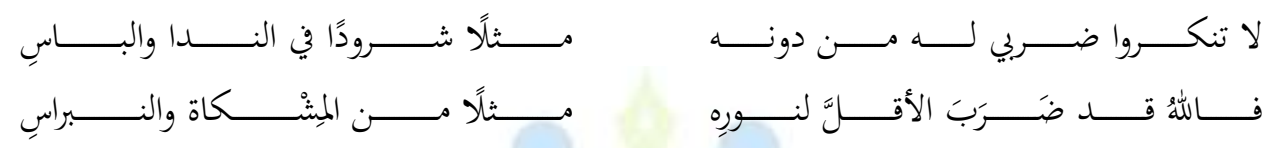

تلك الصور الشعرية والسرعة البديهية للشاعر في الرد والقدرة على توليد المعاني أصابت الفيلسوف بالذهول

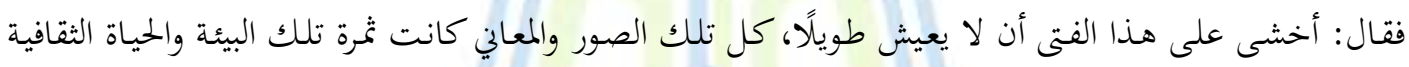

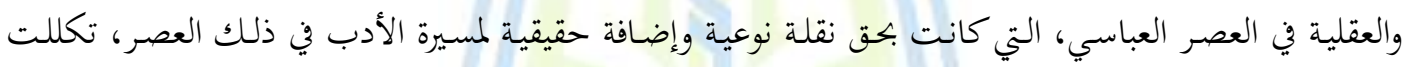

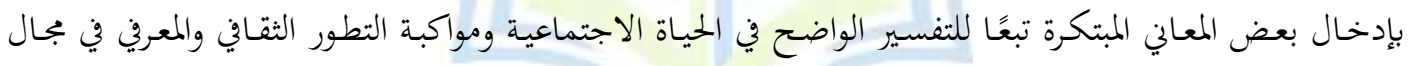

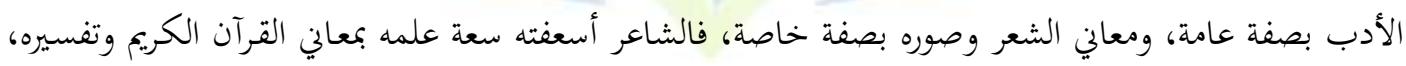

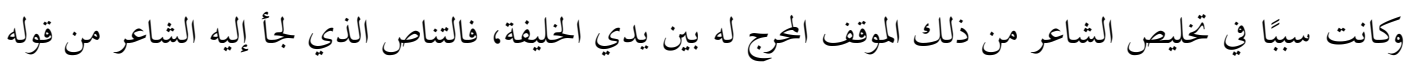

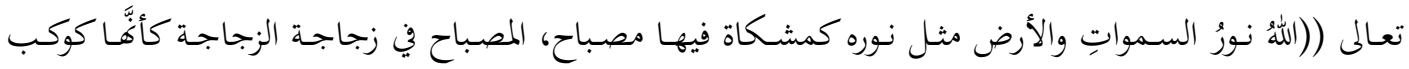

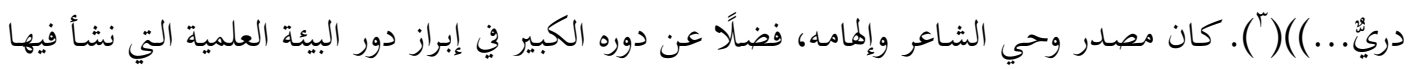

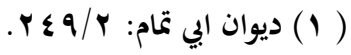

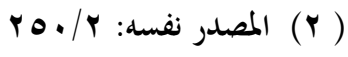

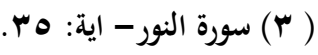


الشاعر وعكس ثقافة الشاعر العالية وقدرته على توليد المعاني والصور الشعرية البليغة، فقد شكلت بيئته الثقافية

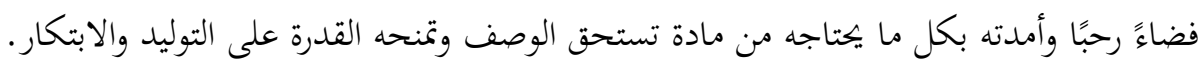

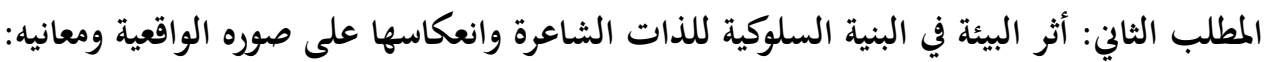

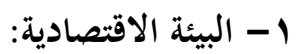

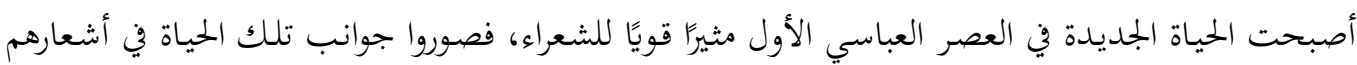

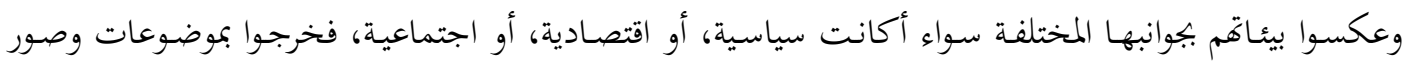

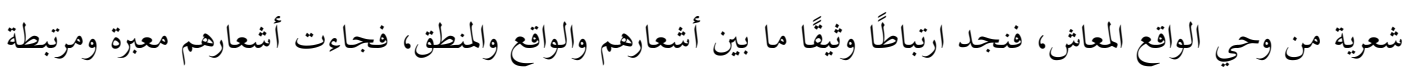

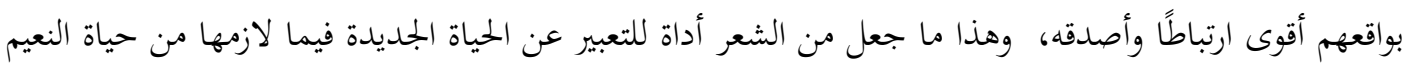

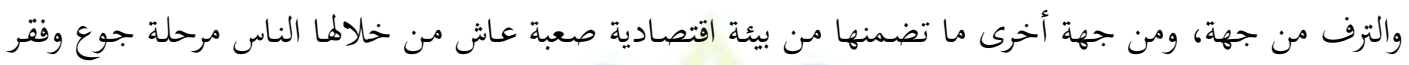

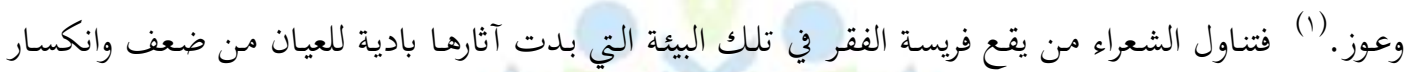

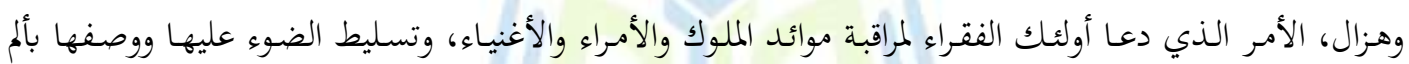

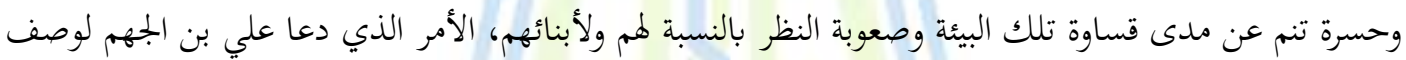
تلك الموائد بقوله: (r)

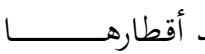

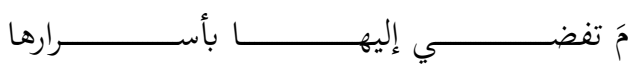

رإها

فارها (الأبص أش بحلب

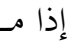

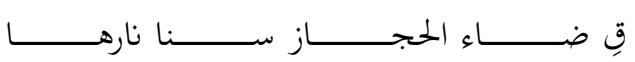
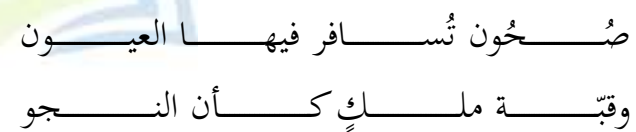

جـ d 2

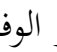
ت

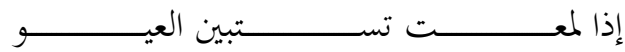

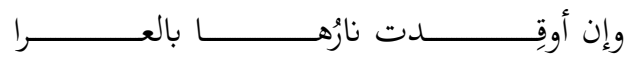

(1 ) ينظر: حياة الشعر في الكوفة، د. يوسف خليف: ص 111.

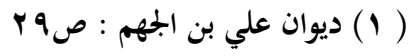

IT

Doi:10.37940/RJIS. 2021.2.1.4 
لقد استحوذت ألفاظ الحسرة والألم في هذا النص على كيان الشاعر والتي بدورها تشير إلى البيئة الاقتصادية التي

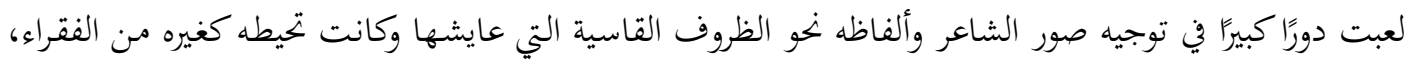

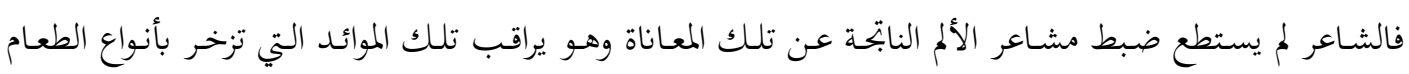

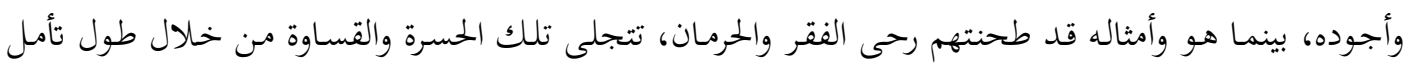

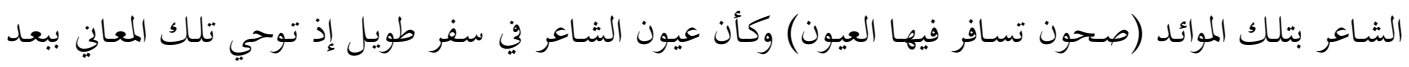

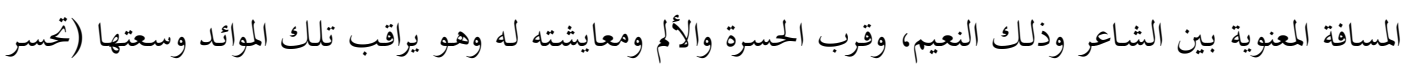

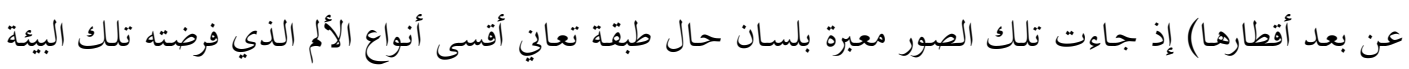
الاقتصادية والتفاوت الطبقي. وهذا أبو المخفف عاذر بن شاكر (')- وكان في عصر المأمون وله أشعار في وصف الخبز (r) - قد بين مدى اتصال

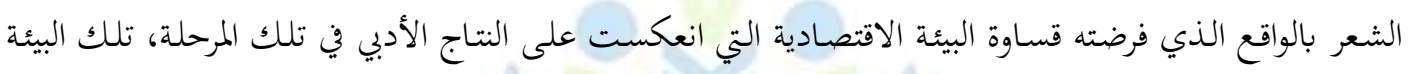

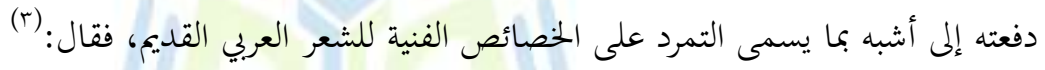

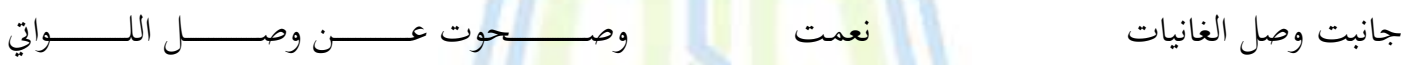

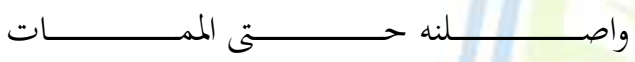

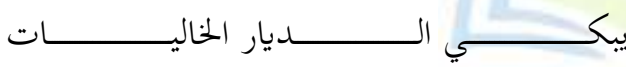

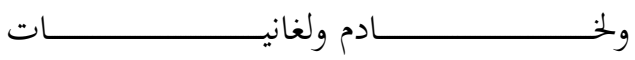

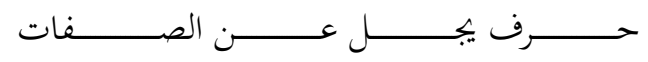
لاة

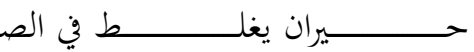
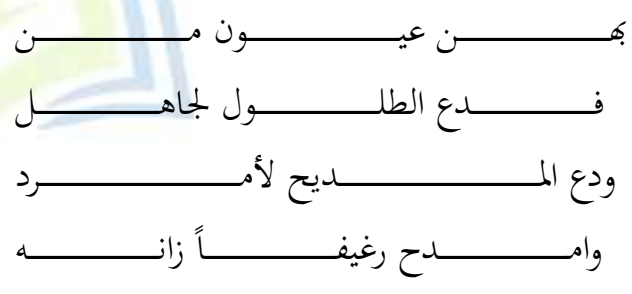

وكأنما يدع الحليم مدلها

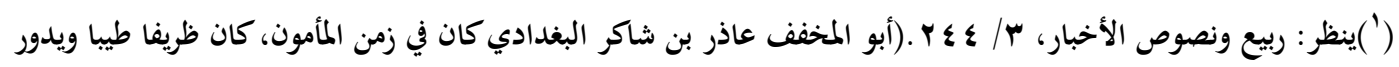

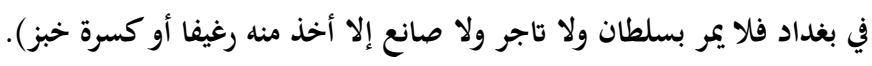

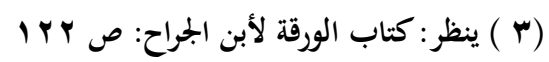

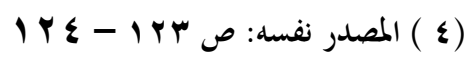

I To

Doi:10.37940/RJIS. 2021.2.1.4 

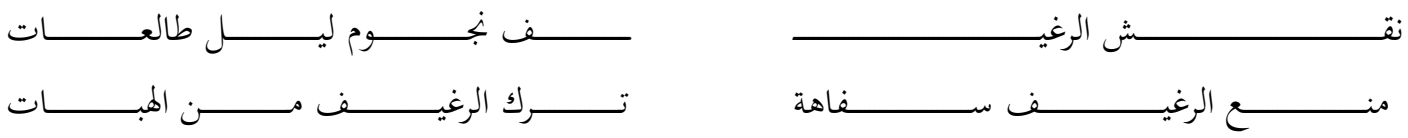

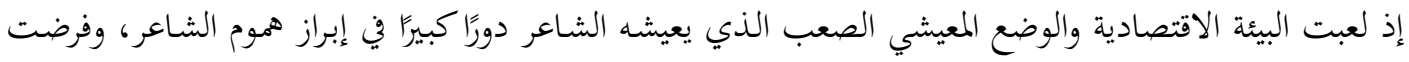

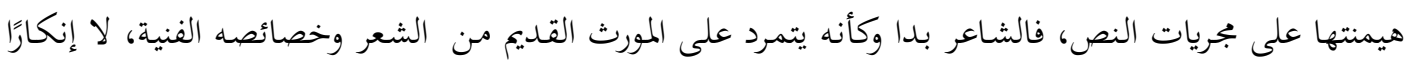

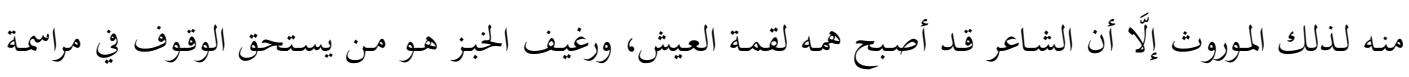

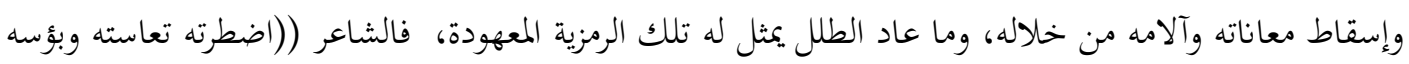

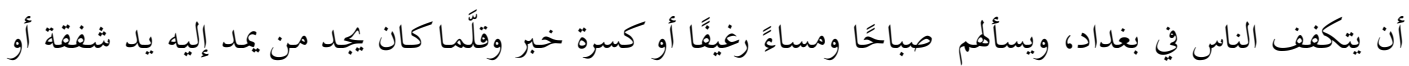

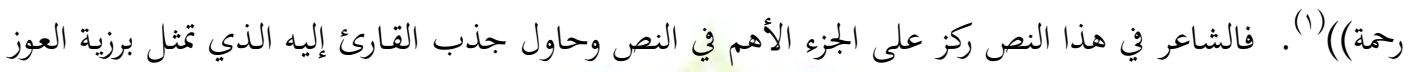

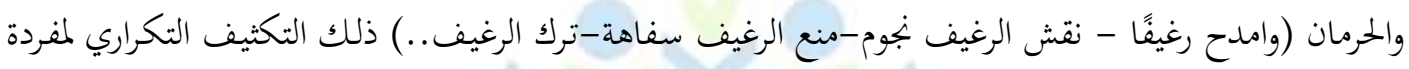

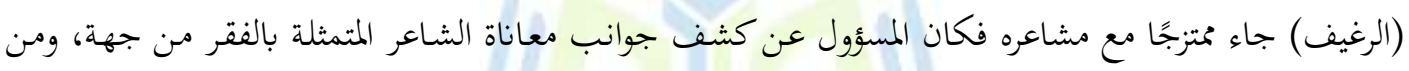

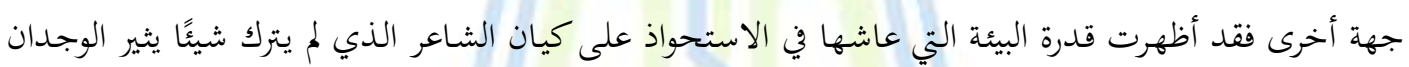

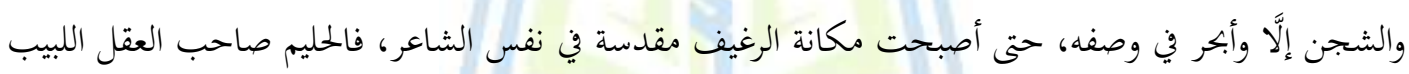

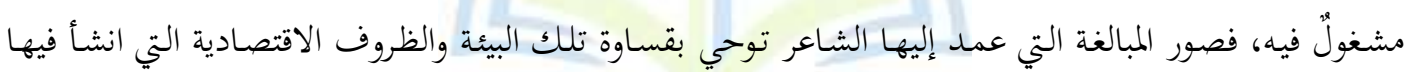

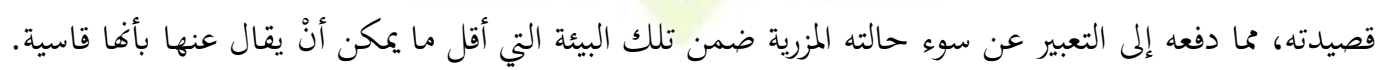

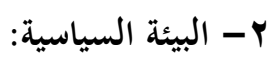

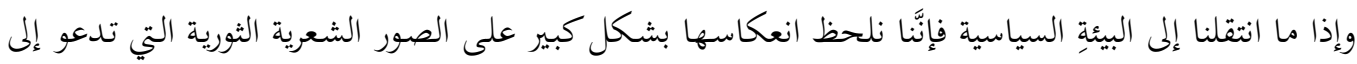

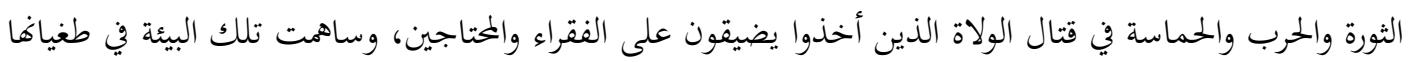

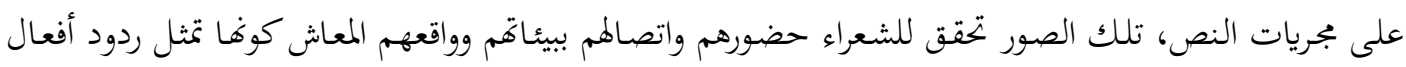

(1 ) الشعر وطوابعه الشعبية على مر العصور - د. شوقي ضيف: ص 19 1 1Y 
خاصة نخو مظاهر البيئة التي تمس كبريائهم، وبرز أبو الندى ( ' ) كأحد المعارضين لتلك البيئة وأصبح متمردًا شديد

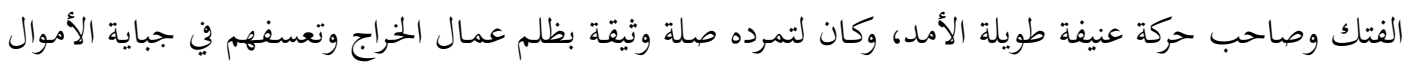

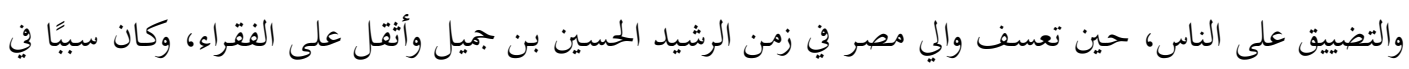

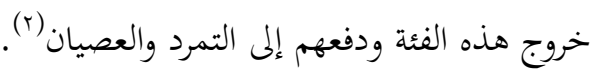

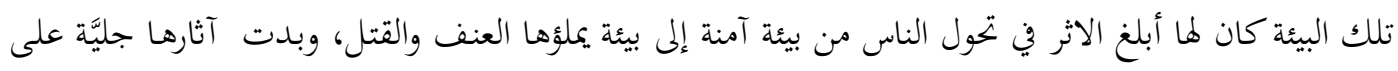

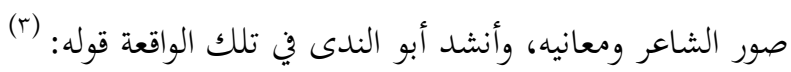

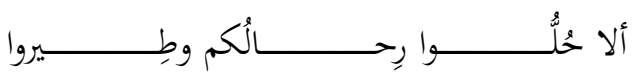

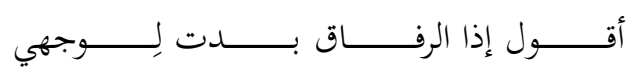

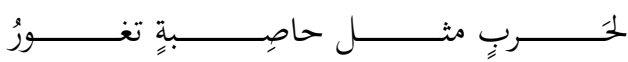

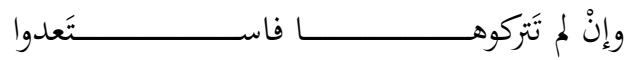

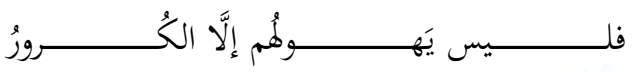

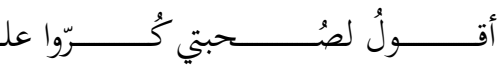

فقد استطاع الشاعر في هذا النص أنْ يستحضر صور الحياة السياسية المليئة بالظمل والاضطهاد؛ الأمر الذي جعلها

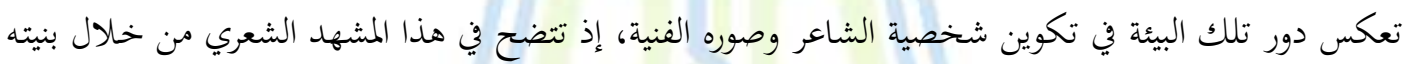

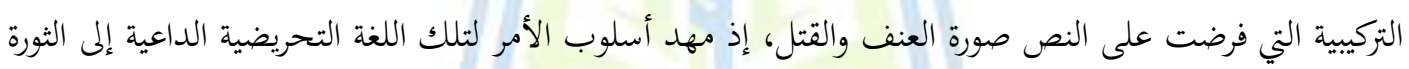

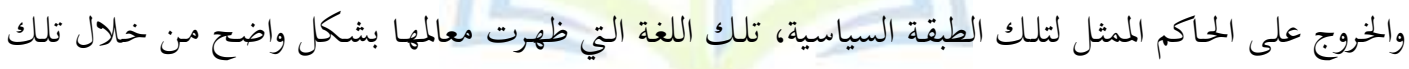

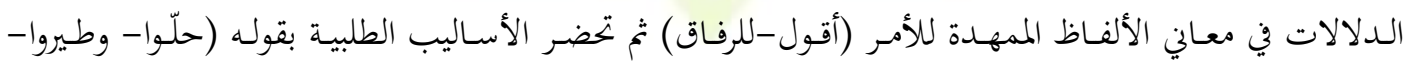

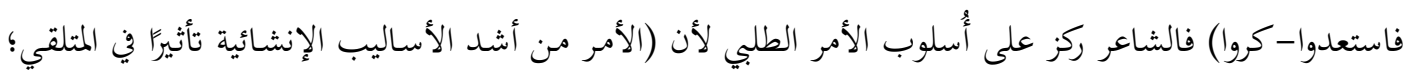

(') ينظر : الولاة والقضاة، / / ـ 11. (من أهل الحوف مولى بَليَّ وكان في زمن الرشيد، خرج عن طاعة الأمير الحسين بن جميل

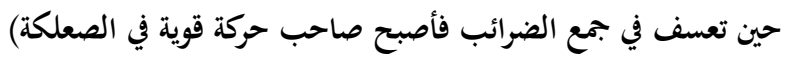

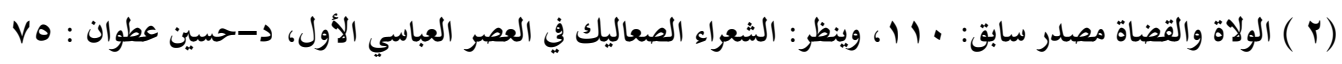

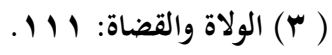

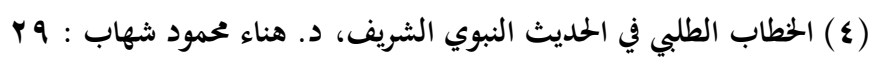
ITV 


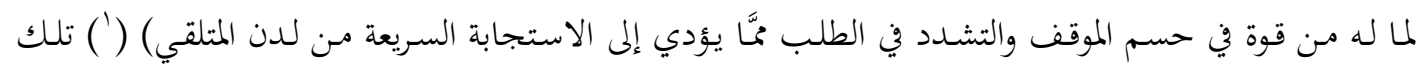

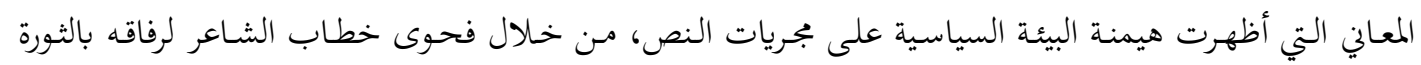

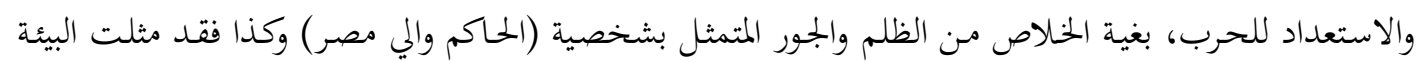

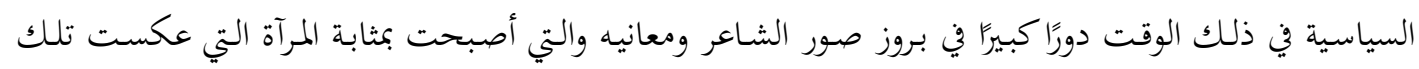

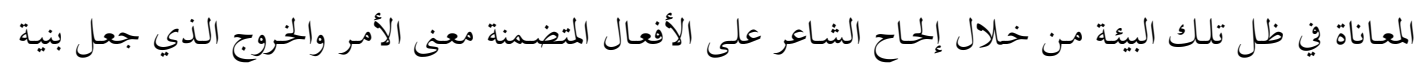

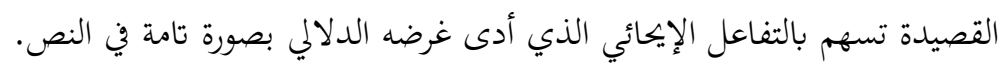

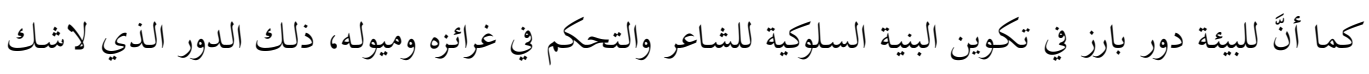

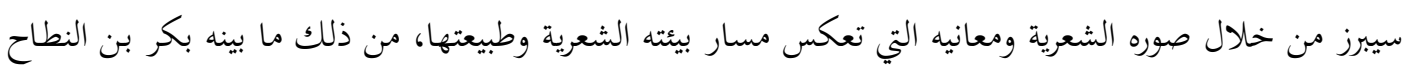
(r) (r)

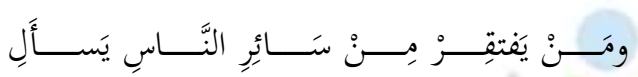

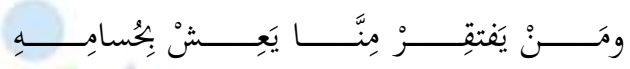

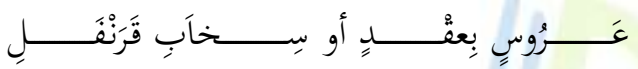

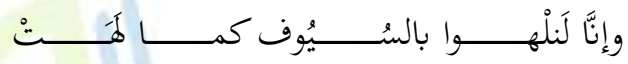

فالجانب السياسي الذي فرضته السلطة في ذلك الوقت وجد تضاربًا وتنافرًا مع بيئة العز والإباء التي تربى عليها

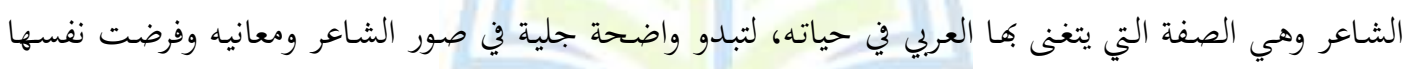

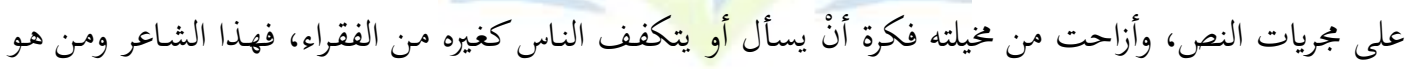

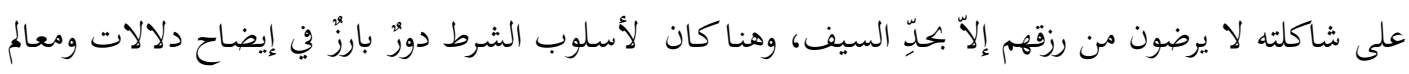

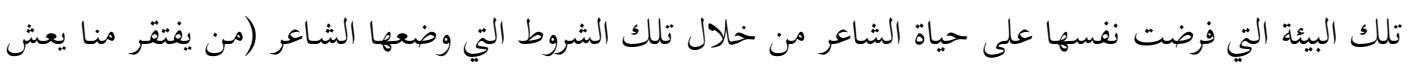

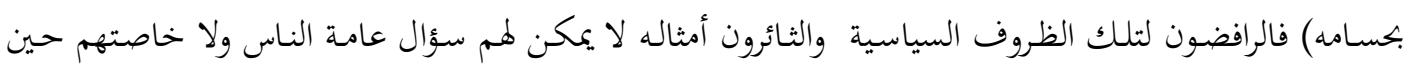

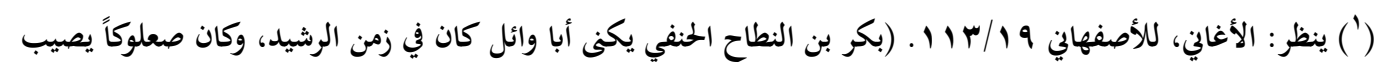

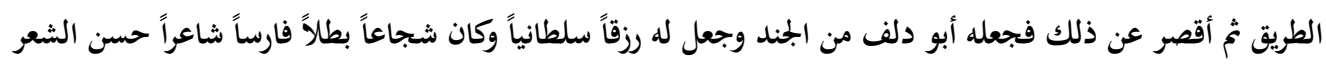
والتصرف فيه كثير الوصف لنفسه بالشجاعة والإقدام)

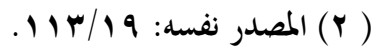

IYN

Doi:10.37940/RJIS. 2021.2.1.4 
تطحنهم رحى الفقر والحرمان، بل هم يستخرجون قوقم بحد السيف الذي يعد وسيلة استغنائهم عن الناس، في

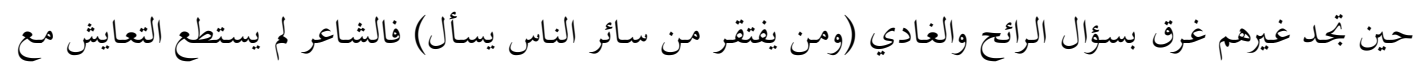

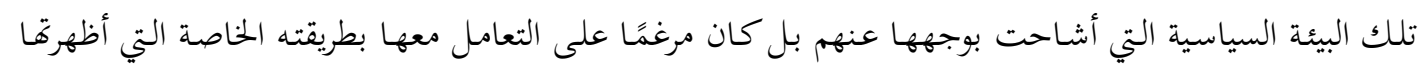
معاني النص وأساليب الشرط التي اتبعها في عكس صورة تلك البيئة.

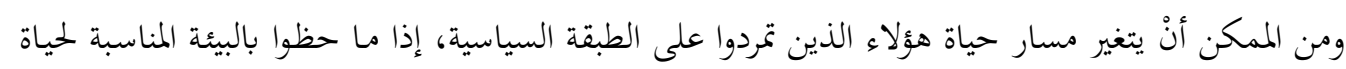

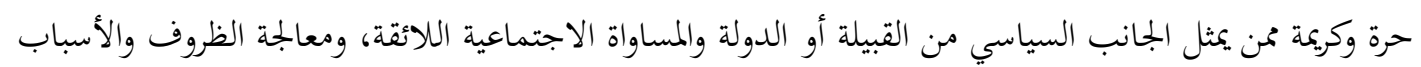

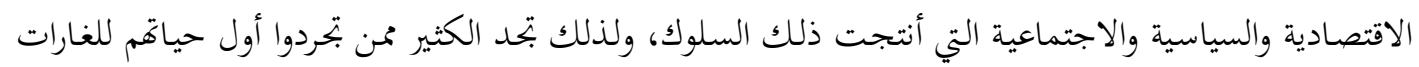

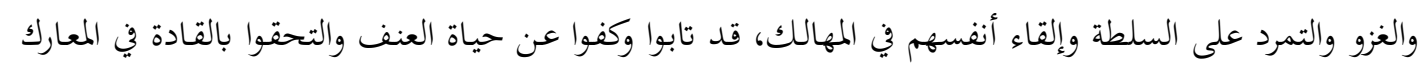

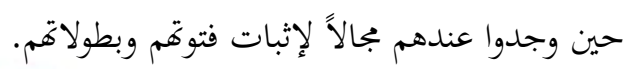

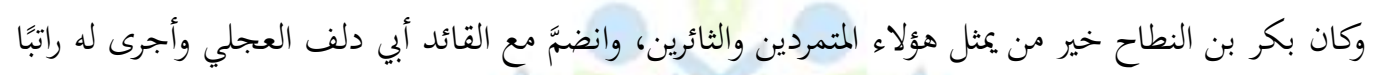
إذ لعبت البيئة الجديدة والحياة السياسية التي حصل عليها الشاعر واكتنفته بالرعاية والمكانة الاجتماعية اللائقة دورًا

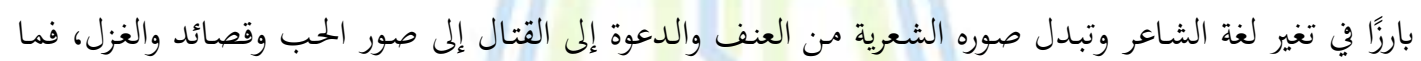

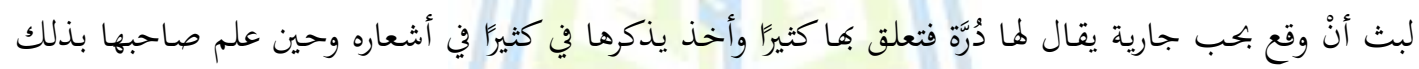

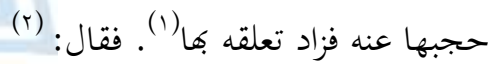

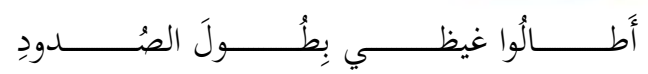

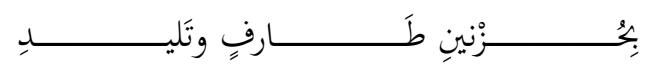

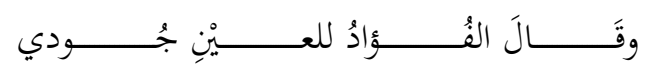

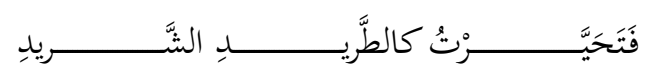

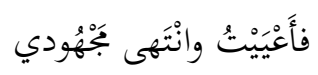

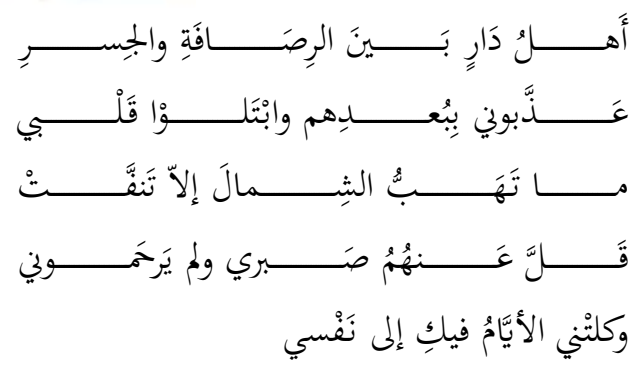

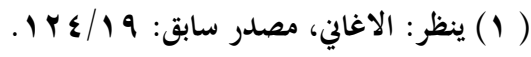

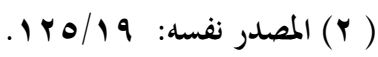


ففي هذا النص نلحظ أثر البيئة الجديدة في الشاعر ودورها في تغيير لغة خطاب الشاعر وشخصيته بشكل عام،

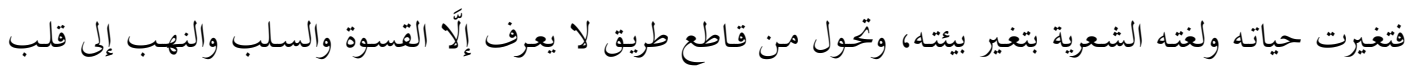

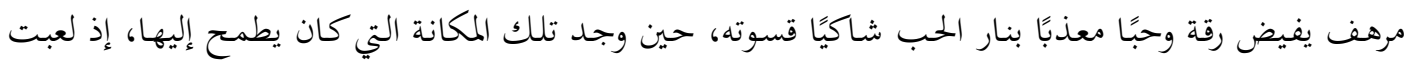

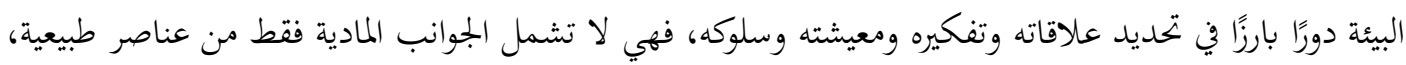

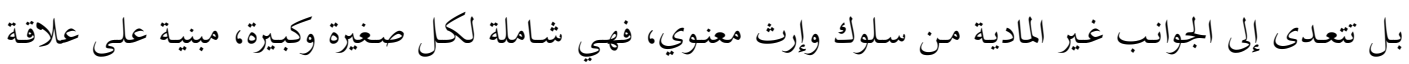

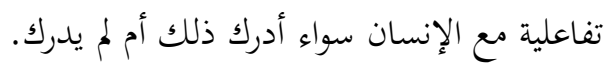

\section{الخاتمة}

وهكذا نكون قد وصلنا بفضل الله وتوفيقه إلى فاية هذه الدراسة الموسومة بـ (أثر البيئة في شعراء العصر العباسي

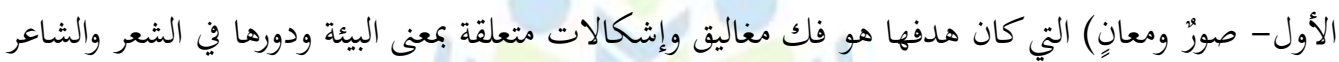

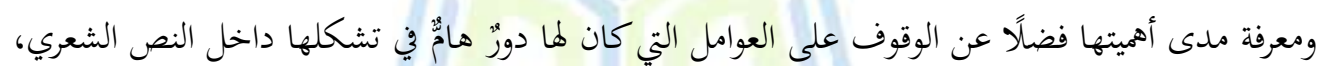

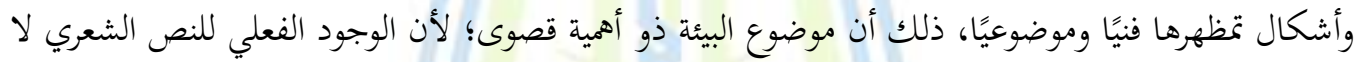

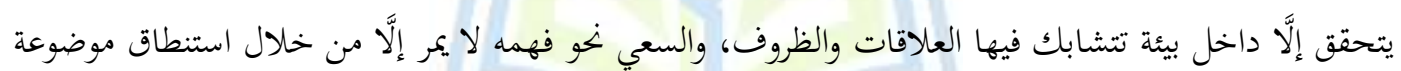

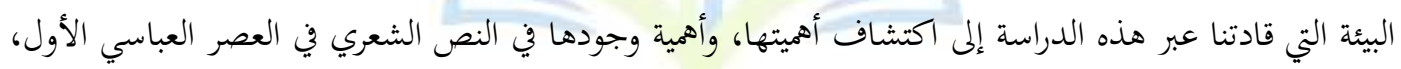
حيث خرجت هذه الدراسة بنتائج أهمها:

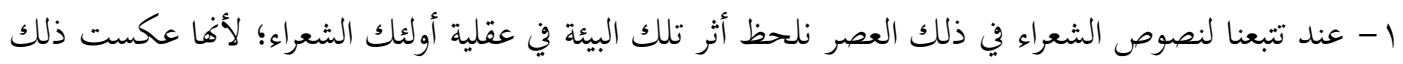

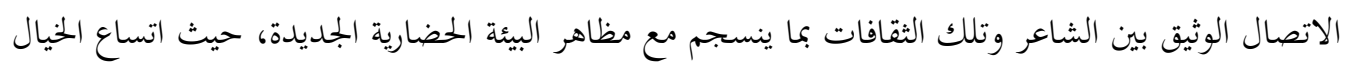

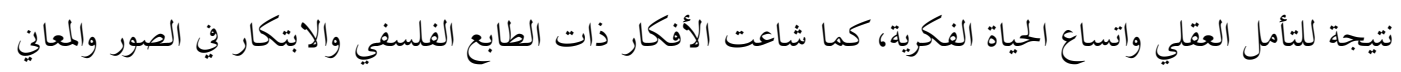
التي تتواءم وحجم التطور الثقافي والفكري في ذلك العصر.

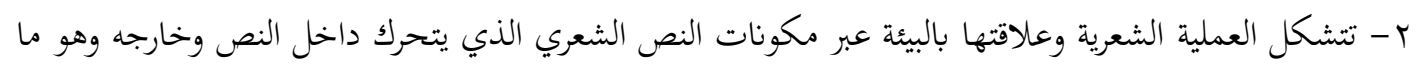
يؤدي في النهاية إلى معرفة أنماط تشكل البيئة داخل النص الشعري واكتشاف فاعليتها وحركيتها؛ كون تشكلها هو تشكل معرفي ناتج عن علاقة البيئة بالشعر.

$1 \%$.

Doi:10.37940/RJIS. 2021.2.1.4 
ب- اثبتت هذه الدراسة أن البيئة وسط حيوي لا غنى للشعر عنه ويُعدّ هذا الوسط رافدًا من روافد إبداعه فمن

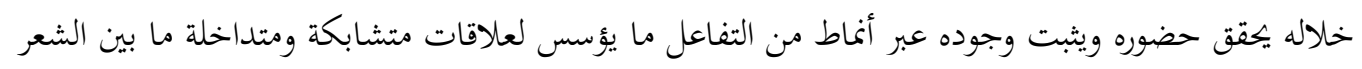
والبيئة من خلال تأثير أحدهما في الآخر.

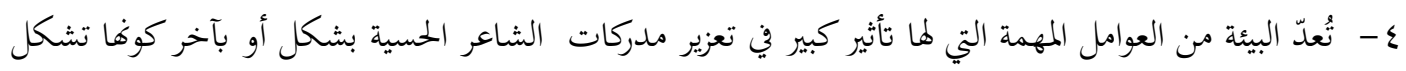
مصدرًا ملهمًا لخياله وإبداعه الشعري وتعزيز صوره وأفكاره. ه- إنَّ الابداع الشعري يتحقق بتفاعل الذات الشاعرة مع بيئتها وأنَّ قراءة ماهية الشعر وفاعليته الحقيقية إنما تبدأ

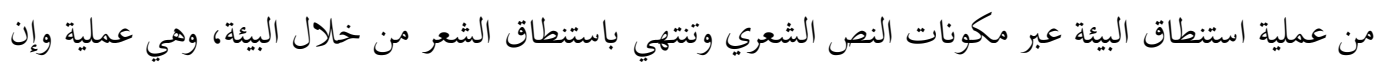

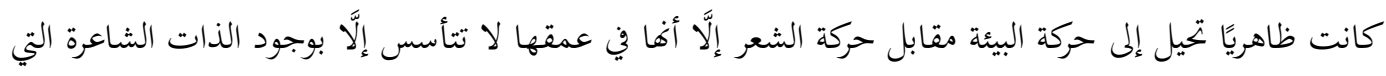

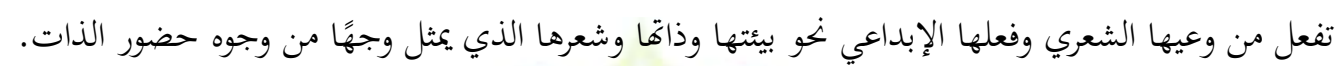

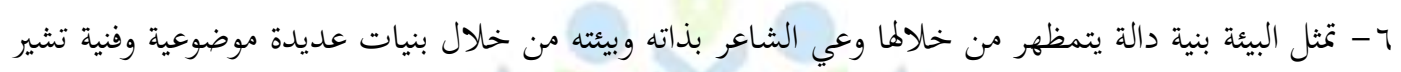

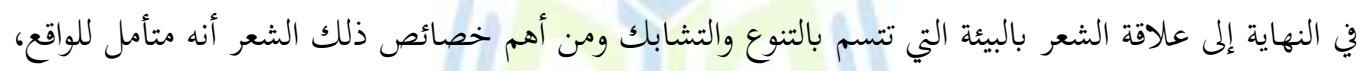
مدرك لوضع الذات فيه.

V- الكشف عن مظاهر تشكل البيئة وتحديد أشكاها يقودنا إلى تحديد طبيعة النص الشعري ونوع تلك العلاقة

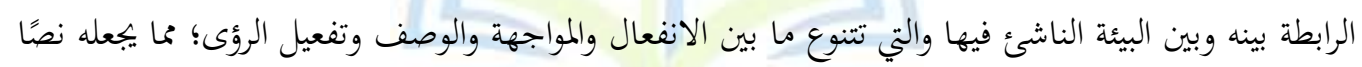
متفاعلاً مع الواقع مصورًا له. 


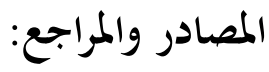

- القرآن الكريع.

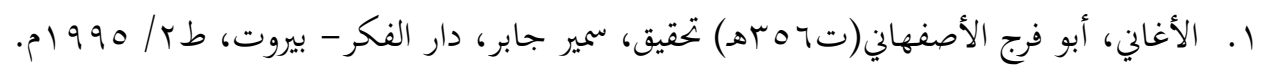

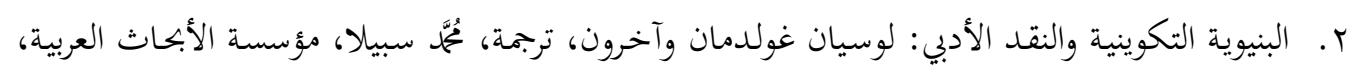

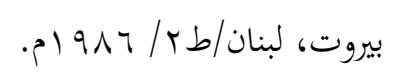

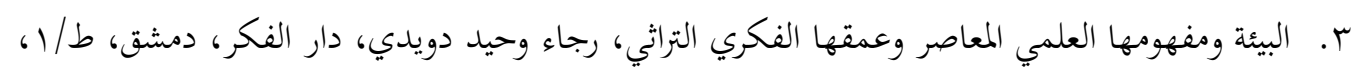

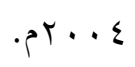

ع. ت تاج العروس من جواهر القاموس، محمّد بن محمّد بن عبد الرزّاق الحسيني، أبو الفيض، الملقّب بمرتضى،

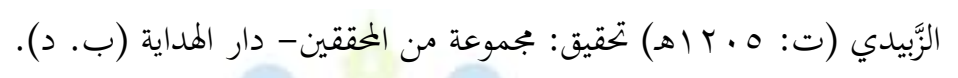

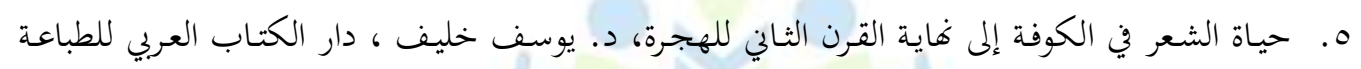

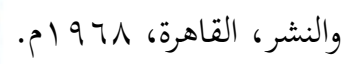
T. الخطاب الطلبي في الحديث النبوي الشريف، دراسة بلاغية في متن صحيح البخاري، د. هناء محمود

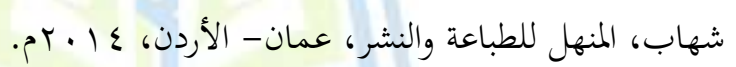

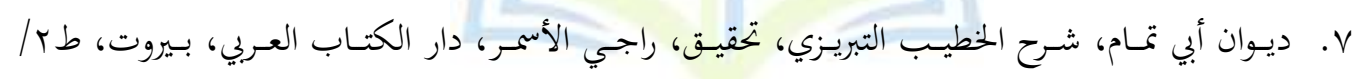
$.0199 \leqslant 601 \leqslant 14$

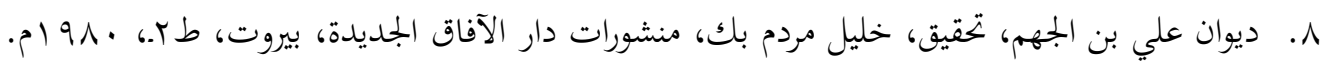

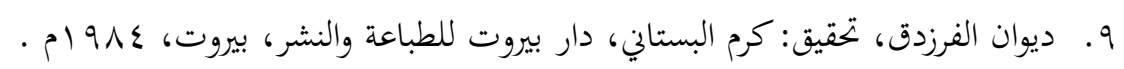

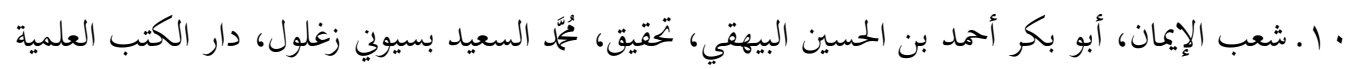

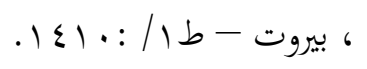

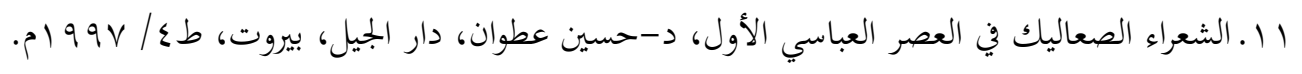

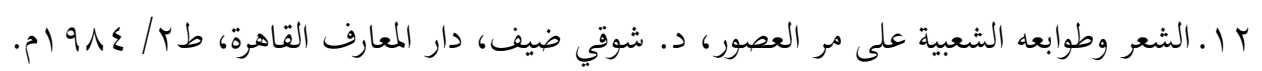




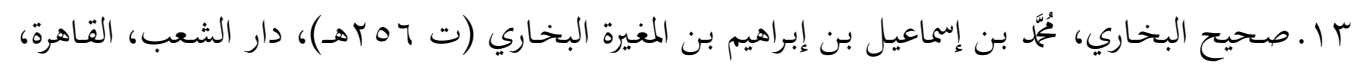

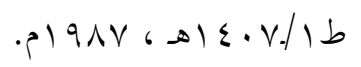

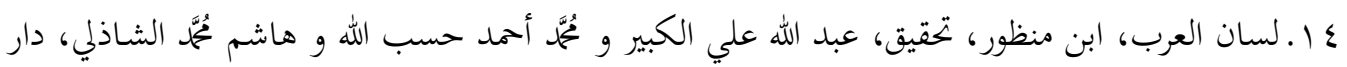

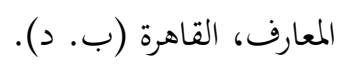

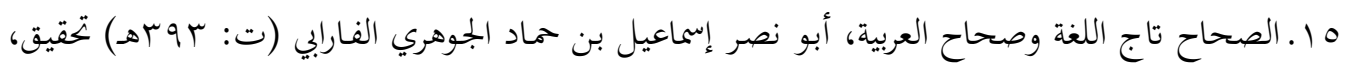

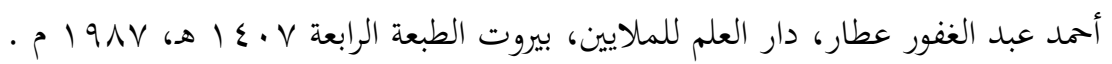

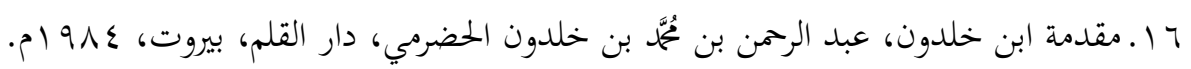

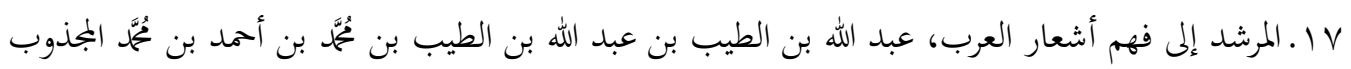

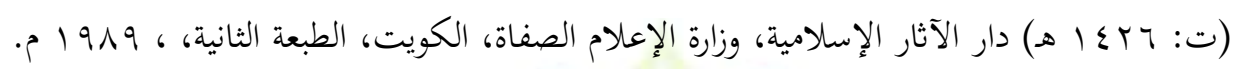

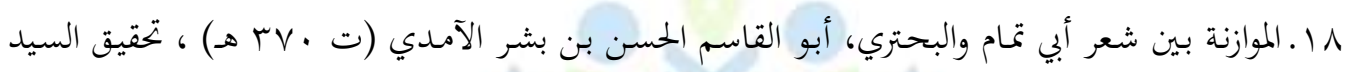

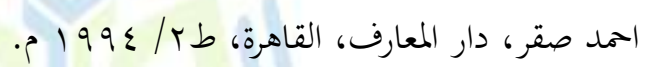

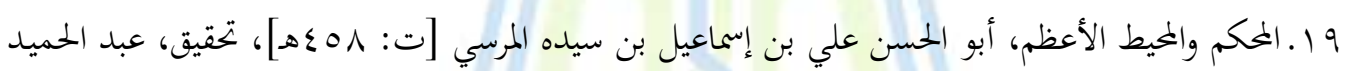

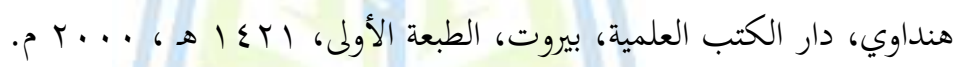

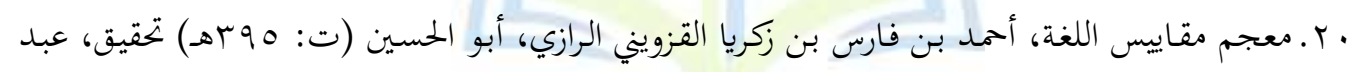

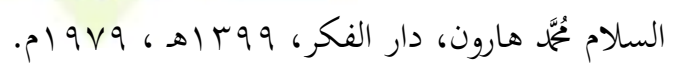

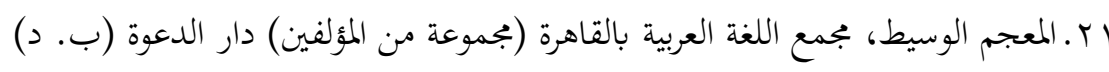

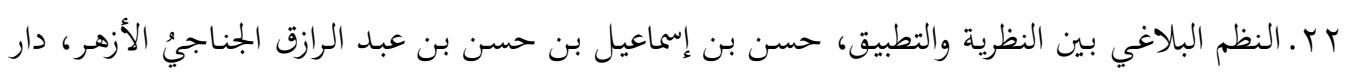

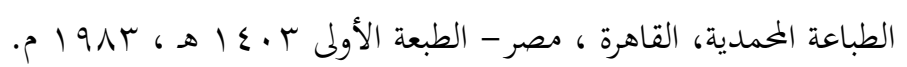

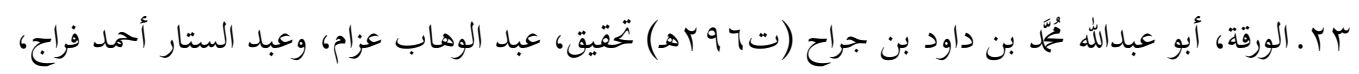

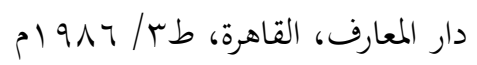

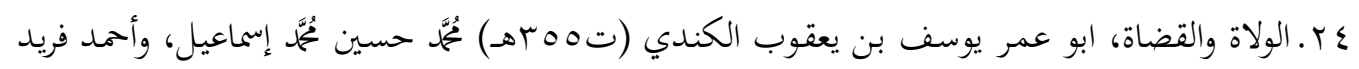

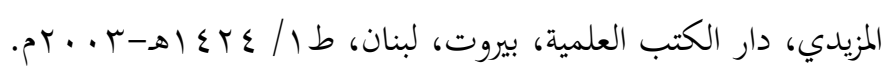

